\title{
Weight loss in elderly women in low-level care and its association with transfer to high-level care and mortality
}

This article was published in the following Dove Press journal:

Clinical Interventions in Aging

7 December 20II

Number of times this article has been viewed

Julie L Woods'

Sandra Iuliano-Burns ${ }^{2}$

Karen Z Walker'

'Department of Nutrition and Dietetics, Monash University, Clayton;

${ }^{2}$ Endocrine Centre of Excellence, Department of Medicine, Austin Health, University of Melbourne, West Heidelberg, Victoria, Australia

Correspondence: Karen Z Walker Department of Nutrition and Dietetics, Monash University, Level 5, Block E, Monash Medical Centre,

246 Clayton Rd, Clayton, Melbourne,

Victoria, Australia 3168

Tel +6I39594 7077

$\mathrm{Fax}+61395946509$

Email karen.walker@monash.edu
Background: The purpose of this study was to determine whether unintentional weight loss in older women predicts an imminent transition out of low-level care (either to higher-level care or by mortality).

Methods: Fifty-three Australian women, ambulatory while living in low-level care and requiring minimal assistance, were studied. At baseline, when the women were aged (mean \pm standard deviation) $86.2 \pm 5.3$ years, body composition was assessed by dual energy X-ray absorptiometry, dietary intake was determined by a three-day weighed food record, a venous blood sample was taken, and both muscle strength and physical functioning were measured. The women were then followed up for 143 weeks to record the composite outcome of transfer to high-level care or mortality.

Results: During follow-up, unintended loss of body weight occurred in $60 \%$ of the women, with a mean weight loss of $-4.6 \pm 3.6 \mathrm{~kg}$. Seven women $(13.2 \%)$ died, and seven needed transfer to high-level care. At baseline, those who subsequently lost weight had a higher body mass index $(P<0.01)$ because they were shorter $(P<0.05)$ but not heavier than the other women. Analysis of their dietary pattern revealed a lower dietary energy $(P<0.05)$ and protein intake $(P<0.01)$. The women who lost weight also had lower hip abductor strength $(P<0.01)$, took longer to stand and walk $(P<0.05)$, and showed a slower walking speed $(P<0.01)$. Their plasma C-reactive protein was higher $(P<0.05)$ and their serum albumin was lower $(P<0.01)$ than women who did not lose weight. Nonintentional weight loss was a significant predictor of death or transfer to high care (hazards ratio $0.095, P=0.02$ ).

Conclusion: Weight loss in older women predicts adverse outcomes, so should be closely monitored.

Keywords: aged care, weight loss, mortality, high care

\section{Introduction}

Weight loss in the aged is relatively common. Older people are susceptible to weight loss following stress, illness, loss of a spouse, or as a result of the ageing process itself, which can decrease appetite and reduce taste and smell. ${ }^{1-3}$ Smoking or the presence of disability exacerbates this process, ${ }^{3}$ as does dementia and the side effects of polypharmacy. ${ }^{2}$ Previous studies indicate that weight loss is associated with a higher risk of mortality, both in community-dwelling ${ }^{3-6}$ and institutionalized older people living in high-level care. ${ }^{7}$ However, in Australia, one quarter of the people (about 39,600) living in care reside in establishments providing low-level rather than high-level care. ${ }^{8}$ Low-level care provides accommodation and assistance with personal care, but nursing support is limited ${ }^{8}$ It is not known whether the occurrence 
of unintentional weight loss in older people living in these circumstances is an indicator of increased risk of mortality or of the need for higher levels of care. This question has importance because their transfer to more intensive care with 24-hour nursing is associated with a substantially greater health cost (approximately \$A604 per week) and a reduced quality of life. ${ }^{9}$ Therefore, the purpose of this study was to evaluate the associations between weight loss and transfer to high-level care or risk of mortality in a cohort of older Australian women residing in low-level care.

\section{Materials and methods}

\section{Study design and participants}

Participants were elderly women from 14 low-level aged care facilities in metropolitan Melbourne. Low-level care provides accommodation, assistance with personal care, and basic nursing care (eg, medication and health monitoring), but does not provide 24-hour nursing care. ${ }^{8}$

The present study was nested within a larger twoyear cluster-design, randomized controlled trial that took place when the women had not been subject to any direct intervention. ${ }^{10}$ Women were enrolled if they were ambulatory and able to self-feed. All were receiving assistance with activities such as personal care, whether this was required or not. While 78 women were recruited, only the 53 for whom there were data for change in body weight were included. These 53 women did not differ in age, body mass index, or medical conditions from the remaining 25 women for whom weight change data were unavailable. Data were obtained at the initial, mid-term, and final assessment of participants enrolled in the larger randomized controlled trial. The study was approved by the Human Research Ethics Committee, Austin Health, and by the Standing Committee on Ethics in Research involving Humans, Monash University.

\section{Weight assessment and baseline characteristics}

Body weight was taken at baseline and during the 143 weeks of follow-up. ${ }^{10}$ Women were excluded if weight had not been assessed on at least two occasions. Body mass index was calculated as body weight $(\mathrm{kg}) /$ height $(\mathrm{m})$ squared. A whole body densitometry scan was also taken at baseline ${ }^{11}$ and analyzed by a single radiographer. Appendicular skeletal muscle mass (ASM) was calculated from the sum of lean tissue mass for the arms plus the legs ${ }^{11}$ so that a total skeletal muscle mass could then be determined. ${ }^{12}$ To ascertain if sarcopenia was present, ASM was adjusted for stature (ASM/height $\left(\mathrm{kg} / \mathrm{m}^{2}\right)^{13}$ and percentage skeletal muscle was also computed. ${ }^{14}$ Body composition data from an Australian female reference group provided cutoff values. ${ }^{11}$

\section{Nutritional intake}

Trained dietitians collected 3-day records based on the weighed intake of all foods, beverages, and food supplements taken at main meals plus morning and afternoon tea, with foods weighed to $\pm 1 \mathrm{~g}$ on digital scales (Soehnle Venezia, Switzerland). A recall of foods and beverages consumed outside set meal times was also taken. Mean daily intake was calculated using the SERVE Nutrition Management System version 5.0.012, 2004 (Serve Nutrition Systems, St Ives, NSW). Nutrient intakes were compared with the estimated average requirements ${ }^{15}$ currently recommended in Australia and New Zealand; the estimated average requirements indicate the amount of a given nutrient needed to meet the requirement of $50 \%$ of the healthy individuals in a population of this age.

\section{Blood collection and laboratory analyses}

Nonfasting, peripheral venous blood was analyzed for 25 hydroxycholecalciferol and albumin at Network Pathology, Austin Health, Melbourne, as described previously. ${ }^{11}$ High sensitivity C-reactive protein was also measured using a Beckman Coulter Synchron LX system chemistry analyser, with reagents and calibrators supplied by Beckman Coulter Inc (Sydney, Australia). The proinflammatory cytokine, interleukin-6, was measured by a commercial automated chemiluminescent enzyme immunoassay using an Immulite Analyser from Diagnostic Products Corporation, Los Angeles, CA. C-reactive protein, interleukin-6, and hemoglobin in nonfasting whole blood was measured at Southern Cross Pathology, Monash Medical Centre, Melbourne.

\section{Abbreviated mental test score}

One qualified researcher assessed cognition using a modified Abbreviated Mental Test Score (AMTS) scored out of $10 .^{16}$ A cutoff score of 7 or 8 is considered to discriminate between cognitive impairment and normality. ${ }^{16}$

\section{Muscle strength}

Muscle strength was determined by the same experienced technician through measurement of the maximal isometric strength of ankle dorsiflexors, knee extensors, and hip abductors in both legs using a hand-held dynamometer, ie, the Nicholas manual muscle tester (Lafayette Instruments, Lafayette, IN), as described previously. ${ }^{17}$ 


\section{Physical function}

Physical function was determined by timed up and go (TUG) and walking speed over a $6 \mathrm{~m}$ distance, as described previously. ${ }^{17}$ One technician performed all function tests.

\section{Other covariates}

Age (in years) was calculated as the difference between the date of first assessment and the reported date of birth. Comorbidity was defined as the number of current chronic conditions based on medical record reporting of cardiovascular disease, stroke, cancer, diabetes, Parkinson's disease, kidney disease, or lung disease. Long-term medications were defined as current medications that were taken to treat a chronic condition. Falls were recorded via a specially designed reporting sheet, providing full fall details including time, activity associated with fall, and outcome of fall. A registered nurse recorded disease conditions and medications from resident medical records maintained at each facility and verified falls data from incident reports.

\section{Outcome data}

The decision to move a woman to high care was made by the consulting medical practitioner on the basis of their clinical requirement for additional care. Data relating to participants' mortality or their transfer to high care were obtained by a registered nurse from medical reports examined every three months throughout the full 143-week follow-up period. A single outcome was recorded for each woman, ie, whether they stayed in low care, moved to high-care, or died.

\section{Data analysis}

Data were analyzed using SPSS for Windows version 19.0 (SPSS Inc, Chicago IL). Descriptive data are given as the mean \pm standard deviation for continuous variables. Differences between groups were tested using the Student's $t$-test for unpaired data. The proportions of women experiencing weight change were examined using frequencies and plots of distribution. Weight loss over 143 weeks was then coded as a single dichotomous variable. Crude assessment of a composite outcome indicative of the end of low-level care (by death or move to high care) was explored using the Kaplan-Meier method, and differences between levels were tested using the log-rank test. Risk of weight loss on the combined outcome of mortality or transfer to high care was estimated by Cox proportional hazard regression, computing hazard ratios, and 95\% confidence intervals. Given the relatively small sample size, only age and a single other covariable were adjusted for in each model explored. The assumption that hazards were proportional was assessed via log-minus-log survival plots.

\section{Results}

At baseline, the women in this study were aged $86.2 \pm 5.3$ years. The youngest was aged 67 years and the oldest 96 years. Although living in low-level care, $38 \%$ had cardiovascular disease, $23 \%$ had previously experienced a stroke, $9 \%$ had lung disease, $8 \%$ had renal disease, $8 \%$ had diabetes, and $6 \%$ had Parkinson's disease, while $11 \%$ had previously had cancer. No women had active cancer as diagnosed by a general practitioner at the time of assessment. The women studied were largely cognitively healthy (mean ATMS score 8.36). Only seven had mild dementia (mean AMTS score $7.1 \pm 1.5$ in this subgroup), with only two having scores $<7$. The presence of these medical conditions at baseline was not associated with any measures of body composition, or with indices of sarcopenia, hematological parameters, dietary intake, ATMS score, falls, strength, or physical functioning. However, the presence of medical conditions was mildly and inversely associated with age $(\mathrm{r}=-0.279, P<0.04)$. Women exhibiting none of the listed medical conditions were slightly older than those who had two conditions $(88.8 \pm 4.3$ years versus $84.2 \pm 4.3$ years, $P<0.05$ ).

During the study, $60 \%$ of the women unintentionally lost weight $(-4.6 \pm 3.6 \mathrm{~kg}$, range $0.5-17.0 \mathrm{~kg}$ ) while $40 \%$ maintained or gained weight (mean weight change $+2.6 \pm 2.1 \mathrm{~kg}$, $P<0.01)$. Overall mean weight change for the whole group was $-1.85 \pm 4.6 \mathrm{~kg}, P<0.01$. Table 1 compares the baseline characteristics of the women who remained weight stable with those who lost weight. Although those who lost weight were older $(P<0.05)$, they did not differ in number of medical conditions, number of medications, number of falls, or ATMS score from those who maintained weight. However, weight losers had a higher initial body mass index $(P<0.01)$ but exhibited no other differences in weight, body composition, or prevalence of sarcopenia (whether defined in absolute or relative terms). Women who lost weight had significantly higher levels of $\mathrm{C}$-reactive protein $(P<0.05)$. Although mean interleukin- 6 was also higher, the difference was not of statistical significance (Table 1). The high body mass index of the weight losers related to their height rather than their adiposity; the weight losers were significantly shorter than the weight maintainers $(P<0.05)$. Differences in nutritional intake were also evident at baseline when women who subsequently lost weight were consuming less dietary energy $(P<0.05)$ and obtaining a lower proportion 
Table I Baseline characteristics for elderly, institutionalized women who lost weight compared with those who did not lose weight

\begin{tabular}{|c|c|c|}
\hline Variable & $\begin{array}{l}\text { Weight loss } \\
(n=32)\end{array}$ & $\begin{array}{l}\text { No weight loss } \\
(n=2 I)\end{array}$ \\
\hline Age (years) & $87.3 \pm 5.4$ & $84.4 \pm 4.7^{*}$ \\
\hline Number of medical conditions ${ }^{\mathrm{a}}$ & $\mathrm{I} . \mathrm{I} \pm 0.8$ & $1.2 \pm 0.9$ \\
\hline Number of medications $s^{\mathrm{b}}$ & $9.5 \pm 4.1$ & $8.9 \pm 3.8$ \\
\hline Height $(m)$ & $1.52 \pm 0.7$ & $1.55 \pm 0.6 *$ \\
\hline Weight (kg) & $64.2 \pm 11.4$ & $59.7 \pm 9.9$ \\
\hline BMI $\left(\mathrm{kg} / \mathrm{m}^{2}\right)$ & $28.0 \pm 4.6$ & $24.7 \pm 3.5^{* *}$ \\
\hline Total fat $(\mathrm{kg})$ & $25.2 \pm 7.7$ & $21.9 \pm 7.7$ \\
\hline Total LTM (kg) & $35.7 \pm 4.6$ & $34.9 \pm 3.4$ \\
\hline $\mathrm{ASM} / \mathrm{ht}^{2}$ & $6.30 \pm 0.91$ & $5.87 \pm 0.76$ \\
\hline SMI (\%) & $24.48 \pm 3.0$ & $25.90 \pm 3.65$ \\
\hline AMTS score & $8.2 \pm 1.5$ & $8.7 \pm 1.5$ \\
\hline $25 \mathrm{OHD}(\mathrm{nmol} / \mathrm{L})$ & $46.1 \pm 23.2$ & $47.9 \pm 32.4$ \\
\hline Albumin $(g / L)$ & $38.1 \pm 3.1$ & $40.9 \pm 3.5^{* *}$ \\
\hline Hemoglobin $(g / L)$ & $126.2 \pm 11.9$ & $130.7 \pm 13.8$ \\
\hline IL-6 (pg/mL) & $4.42 \pm 2.82$ & $4.07 \pm 4.07$ \\
\hline CRP (mg/L) & $4.60 \pm 5.29$ & $2.09 \pm 1.38^{*}$ \\
\hline Hip abductor strength (N/kg) & $1.2 \pm 0.3$ & $1.7 \pm 0.5^{* *}$ \\
\hline Walking speed (m/second) & $0.59 \pm 0.16$ & $0.79 \pm 0.26 * *$ \\
\hline Timed up and go (seconds) & $19.4 \pm 7.3$ & $15.4 \pm 5.6^{*}$ \\
\hline Dietary energy (kJ/day) & $5936 \pm 1147$ & $6618 \pm 1088^{*}$ \\
\hline $\begin{array}{l}\text { Dietary energy ( } \% \text { of estimated } \\
\left.\text { requirement }{ }^{c}\right)\end{array}$ & $97.1 \pm 18.1$ & $108.6 \pm 19.9 * *$ \\
\hline Dietary protein $(\mathrm{g} / \mathrm{kg})$ & $0.81 \pm 0.20$ & $1.02 \pm 0.26 * *$ \\
\hline \multicolumn{3}{|c|}{$\begin{array}{l}\text { Notes: Data are given as the mean } \pm \text { standard deviation. } * P<0.05, * * P<0.01 \text {, } \\
* * * P<0.00 \text { I. aMedical conditions confined to those listed in the Methods section; } \\
\text { 'only medications taken over the longer term are included; 'estimated requirement } \\
\text { calculated as previously described. } \\
\text { Abbreviations: AMTS, abbreviated mental test score; ASM, appendicular skeletal } \\
\text { muscle mass; BMI, body mass index; CRP, C-reactive protein; ht', height squared; } \\
\text { IL-6, interleukin 6; LTM, lean soft-tissue mass; SMI (\%), percentage skeletal muscle; } \\
\text { 25OHD, } 25 \text { hydroxycholecalciferol. }\end{array}$} \\
\hline
\end{tabular}

of their estimated energy requirement $(P<0.01)$. They also consumed less protein relative to body weight $(P<0.01)$ than those who maintained weight.

In addition, the weight losers were less physically able. They exhibited lower hip abductor strength $(P<0.01)$, slower walking speed $(P<0.01)$, and a longer TUG $(P<0.05)$ than the women who maintained weight. They also had lower serum albumin $(P<0.01)$ and higher $\mathrm{C}$-reactive protein
$(P<0.05)$ than those who maintained weight, although other biochemical markers did not differ.

During the 143 weeks of follow-up, only 39 of the initial 53 women $(73.6 \%)$ remained in low-level care. Seven women died (13.2\%) and another seven transferred to high-level care. Mean survival time was $131.9 \pm 2.8$ weeks (Table 2). Those who lost weight were more likely to end their low-level care by death or a move to high care $(40.6 \%)$ than those who did not lose weight ( $4.8 \%, P=0.01$, data not shown).

Table 2 presents the body composition changes that took place over the 143-week period, comparing changes in those who lost weight with those who maintained or gained weight. While there was no difference in the loss of lean tissue mass, the weight losers lost significantly more fat mass than the weight maintainers $(P<0.001)$. Moreover, those who lost weight were lost to low-level care either through death $(18.8 \%)$ or from transfer to high care $(21.9 \%)$ significantly earlier $(125.9 \pm 23.2$ weeks $)$ than those who did not experience weight loss $(140.8 \pm 10.5$ weeks, $P<0.01)$. The difference between these groups equates to 28.4 weeks for those who transferred to high care and 22.6 weeks for those who died. Figure 1 presents a Kaplan-Meier plot comparing the incidence of the composite outcome of death or transfer to high care in the two groups. Little change occurred during the first two years. Thus, after 104 weeks, only four women ended low-level care by death or transfer to high-level care ( $n=3$ and $n=1$, respectively) while $91 \%$ of weight losers and $95 \%$ of weight maintainers remained in low-level care. However, by 143 weeks, all those who had transferred to high care $(100 \%)$ and $86 \%$ of those who died were weight losers $(P=0.03)$.

Few associations were evident in unadjusted univariate Cox proportional hazards analysis between measured variables and the composite outcome of death or transfer to high care. Age, body mass index, number of medical conditions and medications, body composition, measures of sarcopenia and C-reactive protein, dietary intake, number of falls, and hip strength were all unrelated to the composite outcome of

Table 2 Change in body composition in elderly, institutionalized women and occurrence of death or a move to high care over a period of 143 weeks

\begin{tabular}{|c|c|c|c|}
\hline Parameter & $\begin{array}{l}\text { Weight loss } \\
(\mathrm{n}=32)\end{array}$ & $\begin{array}{l}\text { No weight loss } \\
(n=21)\end{array}$ & Total group \\
\hline Total weight change $(\mathrm{kg})$ & $-4.6 \pm 3.6$ & $2.4 \pm 2.1 * *$ & $-1.85 \pm 4.6$ \\
\hline Change in LTM $(\mathrm{kg})$ & $0.10 \pm 1.5$ & $0.65 \pm 1.8$ & $0.32 \pm 1.6$ \\
\hline Change in total fat (kg) & $-3.1 \pm 2.9$ & $2.1 \pm 3.2^{* * *}$ & $-0.99 \pm 3.9$ \\
\hline Time until death or move to high care (weeks) & $125.9 \pm 23.2$ & $140.8 \pm 10.5^{* *}$ & $131.9 \pm 2.814$ \\
\hline
\end{tabular}

Notes: Data are the mean \pm standard deviation. $* P<0.05$, $* * P<0.01$, ${ }^{* * *} P<0.001$ when the weight loss group is compared with the group experiencing no weight loss. Abbreviation: LTM, lean soft-tissue mass. 


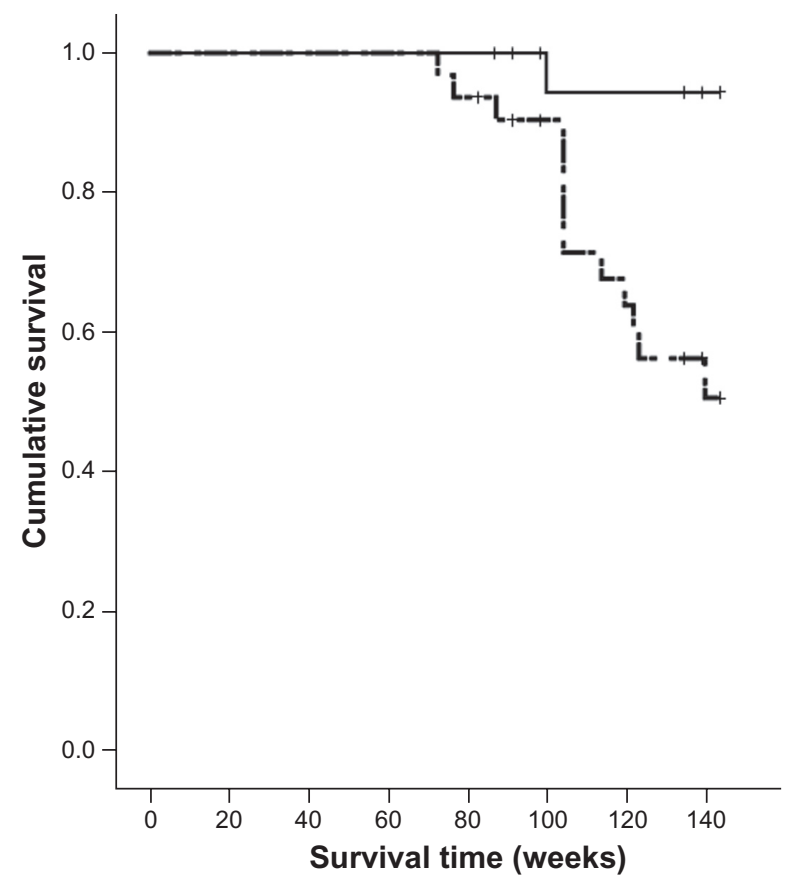

Figure I Kaplan-Meier plot comparing the incidence of death or transfer to high-level care in elderly women $(n=53)$ who experienced weight loss (hatched line) compared with those who experienced no weight loss (solid line) over a 143-week period. Note: Marked lines have been censored ( $P<0.01$, log rank, Mantel Cox).

mortality or transfer to high care (data not shown). The one major association to emerge was with weight loss (hazards ratio $0.095, P=0.02$ ) which significantly predicted death or transfer to high care (Table 3 ). Adjustment for age or for age plus energy intake (or percent estimated energy requirement) did not alter this relationship. Adjustment for age and hip strength reduced the hazards ratio, as did adjustment for age plus height or age plus albumin. Adjustment for age plus C-reactive protein or age plus TUG had only a small attenuating effect. However, none of these additional variables proved to be a significant predictor in any of the models examined. Weight loss thus remained the best predictor of death or increased disability.

Table 3 Associations between weight loss (reference) and mortality or transfer to high care in elderly, institutionalized women

\begin{tabular}{llll}
\hline Model adjustment & HR & $\mathbf{9 5 \%} \mathbf{C l}$ & $\mathbf{P}$ \\
\hline Unadjusted & 0.095 & $0.0 \mathrm{I}-0.73$ & 0.02 \\
Age & 0.090 & $0.0 \mathrm{I}-0.70$ & 0.02 \\
Age, albumin & 0.069 & $0.0 \mathrm{I}-0.6 \mathrm{I}$ & 0.02 \\
Age, height & 0.084 & $0.0 \mathrm{I}-0.66$ & 0.02 \\
Age, BMI & 0.082 & $0.0 \mathrm{I}-0.65$ & 0.02 \\
Age, CRP & 0.110 & $0.0 \mathrm{I}-0.90$ & 0.04 \\
Age, hip strength & 0.059 & $0.006-0.57$ & 0.01 \\
Age, walking speed & 0.089 & $0.0 \mathrm{I}-0.82$ & 0.03 \\
Age, TUG & 0.131 & $0.02-1.07$ & 0.06 \\
Age, dietary energy & 0.094 & $0.01-0.74$ & 0.03 \\
\hline
\end{tabular}

Abbreviations: $\mathrm{BMI}$, body mass index; $\mathrm{Cl}$, confidence interval; $\mathrm{CRP}, \mathrm{C}$-reactive protein; HR, hazards ratio; TUG, timed up and go.

\section{Discussion}

Our findings indicate that in a group of older and mainly cognitively healthy women, those who lost weight had a higher risk of ending their stay in low-level care through mortality or transfer to high care than those who did not lose weight. Moreover, those who experienced weight loss were those whose mean baseline body mass index was within the "overweight" range. These relatively heavy women may possibly be overlooked as having a potentially poor prognosis because it is more common for a low body mass index to alert clinicians to poor nutritional status. ${ }^{1}$ Our findings suggest that, in this group of older women, any unintentional weight loss, even in those who are overweight, is a cause for concern, needs to be monitored, and should trigger appropriate action from clinicians.

The degree of weight loss experienced by our cohort of aged women in low-level care $(-1.85 \pm 4.6 \mathrm{~kg})$ resembles that reported over a two-year period in Canadian communitydwelling and institutionalized elderly aged $80-89$ years. ${ }^{18}$ Moreover, our finding of earlier death among those who experienced weight loss is consistent with studies for both elderly remaining in the general community ${ }^{3-6}$ and those living in high-level care. ${ }^{7}$ In the latter case, Canadian elderly who lost $>4.5 \mathrm{~kg}$ over two years experienced death earlier than those who either gained weight or whose weight remained stable. A recent report has also indicated that weight loss in the year prior to death is more highly predictive of mortality than weight loss occurring three years earlier. ${ }^{19}$ Even a moderate degree of unintentional weight loss may thus be an important predictor of earlier death across the continuum of elderly care.

Little has previously been reported on the association between weight loss in the elderly and the necessity for transition into care or into higher levels of care. Rajala et $\mathrm{al}^{20}$ found no relationship between weight loss and transfer of elderly people from the community into an old people's home. Nevertheless, they also report that elderly with a body mass index $\leq 22 \mathrm{~kg} / \mathrm{m}^{2}$, suggestive of weight loss, were more likely to be placed in a long-stay hospital ward.

Weight loss in the elderly has been associated with older age, higher weight, longer TUG time, slower walking speed, lower strength, and greater disability (by activities of daily living). ${ }^{3,21,22}$ We previously found that hip abductor strength was associated with functional decline in elderly people. ${ }^{17}$ However, in this present study, hip abductor strength was not associated with mortality or transfer to high care, although those who lost weight had lower hip strength at baseline than weight maintainers. In addition, lean tissue mass and 
indices of sarcopenia were not associated with mortality or transfer to high care, as reported by others. ${ }^{21,22}$ The reason why no association was apparent with sarcopenia is unclear. Although prevalence of absolute sarcopenia in the study population was only $9 \%$, the prevalence of relative sarcopenia was $38 \%$, making the explanation of sample bias unlikely in the latter case.

A frequent cause of weight loss in the elderly is a loss of appetite leading to reduced food intake. ${ }^{2}$ Among Australian women previously studied in low-level care, mean energy intake fell below estimated requirements for $65 \%$ of the women surveyed. ${ }^{10}$ Because the women reported in this study were drawn from the same population, a degree of unintentional weight loss was predictable as a result of this hypocaloric intake. None of the participants was intentionally following a weight reduction diet. Unintentional weight loss, ${ }^{4,23,24}$ but not the intentional weight loss experienced by obese elderly, ${ }^{25}$ is associated with increased mortality.

In elderly people, recent rapid weight loss is often associated with underlying illness. ${ }^{19}$ This can complicate the interpretation of studies in the elderly because it is usually unclear whether the weight loss precipitates or merely reflects the adverse medical condition. ${ }^{26}$ In the present study, we found no difference in number of diseases (or number of medications) between our groups at baseline, although we did do not report the severity of disease. However, C-reactive protein levels were higher in those who lost weight. High C-reactive protein, as a positive acute phase reactant suggests a proinflammatory state. ${ }^{27}$ Although not specifically examined here, C-reactive protein and other biomarkers of inflammation may well have utility in signaling the potential for more adverse health outcomes in elderly women.

Changes to body composition may be of equivalent importance as the weight change per se. ${ }^{26}$ We observed that those who lost weight preserved their lean tissue mass and predominantly lost fat mass, as reported in an earlier study, also in women. ${ }^{28}$ The adverse effects of this weight loss therefore appear unrelated to the development of sarcopenia but to change in body fat stores. While high body fat has numerous adverse effects, ${ }^{29}$ moderate levels of obesity in the elderly impart little increase in mortality, ${ }^{29}$ and accumulation of body fat is associated with the benefits of higher bone mineral density and a slower rate of bone loss. ${ }^{29}$ However, in the present study, although a strong relationship was evident between bone mineral density and total fat $(r=0.6$, $P<0.001$ ), there was no difference in bone mineral density at baseline between those who lost weight and those who did not. Similarly, bone mineral density did not predict death or a move to high care (data not shown).

The cost of providing residential aged care in Australia is increasing. Most of the aged care services budget in 2008/09 (\$10,079 billion) went towards the provision of residential aged care ( $\$ 6654$ billion). ${ }^{8}$ The subsidy per person in high care was $\$ 51,550$ per annum as compared with only $\$ 20,150$ per annum for low-level care. ${ }^{9}$ Preventing or delaying the necessity for transition to high care would therefore result in substantial savings. We observed a time difference of 28.4 weeks, representing a potential saving of $\$ 17,149$ per person.

This study is limited by the small sample size, the focus on women only, relatively short follow-up, and the use of a convenience sample of volunteer participants. However, methodologies used for data collection of weight, body composition, and other measures of nutritional intake and status are all objectively based. This is also the first study of this kind to report on elderly women residing in low-level care.

The results of this study highlight that weight loss can be a signal for higher morbidity and mortality that requires clinical investigation so that interventions to treat underlying causes and to reverse or prevent weight loss can be implemented. They also demonstrate the need for effective weight monitoring in low-level care residents. The accreditation standards for residential care in Australia ${ }^{30}$ require that facilities demonstrate that residents receive adequate nutrition and hydration. Although one expected outcome should be regular weight monitoring of residents, little definitive advice has been provided on frequency of weight measurement or outlining the clinical response needed when a substantive weight change is noted. A more operationalized approach is called for before savings associated with weight loss prevention and delayed transfer to high care can be realized. Where weight loss is identified, there is a need to investigate the causative factors, treat any medical problems, and make changes to the dietary intake to coincide with resident needs. This may require provision of high energy supplements, ie, the addition of higher kilojoule ingredients to regular foods, eg, cream, oil, and sugar, modification of the texture of food so that it can be eaten more readily, and/or increasing physical and social support with eating, which have recently been shown to assist with weight gain and potentially with functional status. ${ }^{31}$

Further research is required to investigate the adverse outcomes of weight loss in low-level care residents more fully (including studies in men) and to develop guidelines for those responsible for care so that measures to prevent weight loss can be established. 


\section{Acknowledgments}

We would like to thank staff and residents of the aged care facilities for their cooperation and participation in the study. We would also like to acknowledge research nurses, Sheila Matthews, Judy Tan, and Kylie King, who sourced medical data on residents, and Bereha Khorda for performing muscle strength and functional testing. The larger trial in which this study was nested was funded by Dairy Australia.

\section{Disclosure}

The authors report no conflicts of interest in this work.

\section{References}

1. Miller S, Wolfe R. The danger of weight loss in the elderly. J Nutr Health Aging. 2008;12:487-491.

2. Bales CW, Ritchie CS. Sarcopenia, weight loss, and nutritional frailty in the elderly. Ann Rev Nutr. 2002;22:309-323.

3. Newman AB, Yanez D, Harris TB, et al. Weight change in old age and its association with mortality. J Am Geriatr Soc. 2001;49:1309-1318.

4. Locher JL, Roth DL, Ritchie CS, et al. Body mass index, weight loss, and mortality in community-dwelling older adults. J Gerontol A Biol Sci Med Sci. 2007;62:1389-1392.

5. Wedick NM, Barrett-Connor E, Knoke JD, Wingard DL. The relationship between weight loss and all-cause mortality in older men and women with and without diabetes mellitus: The Rancho Bernardo Study. J Am Geriatr Soc. 2002;50:1810-1815.

6. Reynolds M, Fredman L, Langenberg P, Magaziner J. Weight, weight change and mortality in a random sample of older community dwelling women. J Am Geriatr Soc. 1999;47:1409-1414.

7. Dwyer JT, Coleman KA, Krall E, et al. Changes in relative weight among institutionalized elderly adults. J Gerontol. 1987;42:246-251.

8. Australian Institute of Health and Welfare. Residential Aged Care in Australia 2008-2009: A Statistical Overview. Canberra, Australia: Australian Institute of Health and Welfare; 2010.

9. Department of Health and Ageing. Report on the Operation of the Aged Care Act 1997: 1 July 2009 to 30 June 2010. Canberra, Australia: Australian Government Printer; 2009.

10. Woods JL, Walker KZ, Iuliano-Burns S, Strauss BJ. Malnutrition on the menu: nutritional status of institutionalised elderly Australians in low-level care. J Nutr Health Aging. 2009;13:693-698.

11. Heymsfield SB, Smith R, Aulet M, et al. Appendicular skeletal muscle mass: measurement by dual-photon absorptiometry. Am J Clin Nutr. 1990;52:214-218.

12. Kim J, Wang Z, Heymsfield SB, et al. Total-body skeletal muscle mass: estimation by a new dual-energy x-ray absorptiometry method. Am J Clin Nutr. 2002;76:378-383.

13. Baumgartner RN, Koehler KM, Gallagher D, et al. Epidemiology of sarcopenia among the elderly in New Mexico. Am J Epidemiol. 1998; 147:755-763.
14. Janssen I, Heymsfield SB, Ross R. Low relative skeletal muscle mass (sarcopenia) in older persons is associated with functional impairment and physical disability. J Am Geriatr Soc. 2002;50:889-896.

15. Department of Health and Ageing, National Health and Medical Research Council. Nutrient Reference Values for Australia and New Zealand. Canberra, Australia: Australian Government Printer; 2006.

16. Hodkinson $\mathrm{H}$. Evaluation of a mental test score for assessment of mental impairment in the elderly. Age Ageing. 1974;1:233-238.

17. Woods JL, Iuliano-Burns S, King SJ, et al. Poor physical function in elderly women in low-level aged care is related to muscle strength rather than to measures of sarcopenia. Clin Interv Aging. 2011;6:67-76.

18. Shatenstein B, Kergoat M-J, Nadon S. Anthropometric changes over 5 years in elderly Canadians by age, gender, and cognitive status. J Gerontol A Biol Sci Med Sci. 2001;56:M483-M488.

19. Bamia C, Halkjær J, Lagiou P, et al. Weight change in later life and risk of death amongst the elderly: the European Prospective Investigation into Cancer and Nutrition-Elderly Network on Ageing and Health study. $J$ Int Med. 2010;268:133-144.

20. Rajala SA, Kanto AJ, Haavisto MV, et al. Body weight and the threeyear prognosis in very old people. Int J Obes. 1990;14:997-1003.

21. Newman AB, Kupelian V, Visser M, et al. Strength, but not muscle mass, is associated with mortality in the Health, Aging and Body Composition Study Cohort. J Gerontol A Biol Sci Med Sci. 2006;6:72-77.

22. Cesari M, Pahor M, Lauretani F, et al. Skeletal muscle and mortality results from the InCHIANTI Study. J Gerontol A Biol Sci Med Sci. 2009;64A:377-384.

23. French SA, Folsom AR, Jeffery RW, Williamson DF. Prospective study of intentionality of weight loss and mortality in older women: The lowa Women's Health Study. Am J Epidemiol. 1999;149:504-514.

24. Knudtson MD, Klein BEK, Klein R, Shankar A. Associations with weight loss and subsequent mortality risk. Ann Epidemiol. 2005; 15:483-491

25. Shea MK, Houston DK, Nicklas BJ, et al. The effect of randomization to weight loss on total mortality in older overweight and obese adults: The ADAPT Study. J Gerontol A Biol Sci Med Sci. 2010;65A:519-525.

26. Richman EL, Stampfer MJ. Weight loss and mortality in the elderly: separating cause and effect. J Int Med. 2010;268:103-105.

27. Padayachee L, Rodseth RN, Biccard BM. A meta-analysis of the utility of C-reactive protein in predicting early, intermediate-term and long term mortality and major adverse cardiac events in vascular surgical patients. Anaesthesia. 2009;64:416-424.

28. Newman AB, Lee JS, Visser M, et al. Weight change and the conservation of lean mass in old age: the Health, Aging and Body Composition Study. Am J Clin Nutr. 2005;82:872-878.

29. Villareal DT, Apovian CM, Kushner RF, Klein S. Obesity in older adults: technical review and position statement of the American Society for Nutrition and NAASO, The Obesity Society. Am J Clin Nutr. 2005;82:923-934.

30. Office of Legislative Drafting and Publishing. Quality of Care Principles 1997. Canberra, Australia: The Attorney-General's Department; 2010.

31. Beck AM, Wijnhoven HAH, Lassen KO. A review of the effect of oral nutrition interventions on both weight change and functional outcomes in older nursing home residents. e-SPEN, Eur e-J Clin Nutr Metab. 2011;6:e101-e105.
Clinical Interventions in Aging

\section{Publish your work in this journal}

Clinical Interventions in Aging is an international, peer-reviewed journal focusing on evidence-based reports on the value or lack thereof of treatments intended to prevent or delay the onset of maladaptive correlates of aging in human beings. This journal is indexed on PubMed Central, MedLine, the American Chemical Society's 'Chemical Abstracts

\section{Dovepress}

Service' (CAS), Scopus and the Elsevier Bibliographic databases. The manuscript management system is completely online and includes a very quick and fair peer-review system, which is all easy to use. Visit http://www.dovepress.com/testimonials.php to read real quotes from published authors. 